\title{
Parenting and Psychiatric Rehabilitation: Can Parents With Severe Mental Illness Benefit From a New Approach?
}

Prepublication for the article:

Van der Ende P.C., Van Busschbach J.T., Nicholson J., Korevaar, E.L. ,Van Weeghel, J.(2014). Parenting and psychiatric rehabilitation: Can parents with severe mental illness benefit from a new approach? Psychiatric Rehabilitation Journal, Vol 37(3), Sep 2014, 201-208 


\section{Abstract}

Objective: The aim of this pilot study was to explore the initial experiences with and impact of Parenting with Success and Satisfaction (PARSS), a psychiatric rehabilitation and recovery based, guided self-help intervention, for parents with severe mental illnesses.

Methods: Changes in the PARSS intervention group $(\mathrm{N}=11)$ were compared with changes in a control group $(\mathrm{N}=15)$ in a nonequivalent control group design. Outcome measures included: parenting satisfaction reported by parents; parenting success reported by mental health practitioners and family members; empowerment as reported by parents, practitioners and family members; and parents’ reported quality of life. Additional process data were obtained on relationship with practitioner, quality of contact, satisfaction with the intervention and fidelity. Results: Parenting satisfaction increased after 1 year for the PARSS group, but not for the control group. Parents' reports of empowerment did not change for either group. The scores of parents' empowerment reported by practitioners and family members increased in the control group, with no such change in the PARSS group. Quality of life improved significantly for the intervention group. Process measures showed that, although PARSS was not always implemented as intended, both parents and practitioners expressed satisfaction with the intervention.

Conclusions and Implications for Practice: The first experiences with PARSS were mixed. This intervention, implemented by mental health practitioners, has the potential to function as a useful tool for supporting parents. Attention must be paid to enhancing intervention implementation and fidelity. 


\section{Introduction}

Parents with disabilities living with severe mental illnesses, like all parents, face a variety of challenges when raising children. With the shift from hospital-based care to community-based mental health programs and a growing awareness of the need to live life according to one's own choices, there are most likely increasing opportunities for people with severe mental illnesses to become parents and care for their children. In the U.S., about two thirds of people meeting criteria for severe mental illness living in the community had children (Nicholson, Biebel, Williams, \& Katz-Leavy, 2004). In the Netherlands, we estimated that $48 \%$ of the population living with severe mental illnesses were parents of children under 18 years of age (Van der Ende, Van Busschbach, Wiersma, \& Korevaar, 2011).

In the past 10 years, the parental role has received increased attention in psychiatric rehabilitation (Ackerson, 2003a; Mowbray, Oyserman, Bybee, MacFarlane, \& Rueda-Riedle, 2001). Several authors emphasize that rehabilitation approaches should address the needs of the person in recovery as a parent (Howard \& Underdown, 2011; Nicholson \& Deveney, 2009). Positive as well as difficult aspects of parenting for adults living with psychiatric disabilities are emphasized by these authors. They and others explored parents' challenges and over the years they developed supportive strategies and programs for parents with psychiatric disabilities (Craig, 2004; Nicholson, Henry, Clayfield, \& Phillips, 2001) and evaluated those (Nicholson, Albert, Gershenson, Williams, \& Biebel, 2009). Practitioners providing related evidence-based interventions for adults with mental illnesses are aware of the issues for adults as parents. For example, Assertive Community Treatment programs have been studied as they provide services 
to parents with mental illnesses (White, McGrew, \& Salyers, 2013). More recently, Jones et al. (2013) introduced online parenting programs for Internet use.

The research focus shifted from the adverse effects of parental mental illness on children toward consideration of the experience and needs of mothers and fathers living with mental health problems, and the development of strategies to support their integration into family and community life (Nicholson, Nason, Calabresi, \& Yando, 1999). Addressing parenting issues in conjunction with parents' mental health needs was concluded to be important when working with this group (Reupert \& Maybery, 2011). Authors also recommended numerous parent-focused services, including family therapy, parenting skills, communication skills training, accessing resources for children, and peer support groups (White et al., 2013; Hinden, Biebel, Nicholson, Henry, \& Katz-Leavy, 2006; Nicholson et al., 2001). In addition to standardized programs for well parents, there is a need for an approach that can support parents living with mental illnesses in focusing on their parental role if they choose, and on the goals for family life they select and prioritize.

The Parenting with Success and Satisfaction (PARSS) intervention has been developed to this end (Van der Ende, Venderink, \& Van Busschbach, 2010). This approach comprises a method that helps parents to explore, choose and realize their rehabilitation goals in the area of parenting. The aim of PARSS is to support individuals in developing skills and accessing the resources necessary to be successful and satisfied in their chosen role and life context—-that is, parenthood and family life. Depending on his or her needs and preferences, a parent in recovery is supported in developing capabilities as a parent along with addressing other life roles and goals. For instance, a parent in recovery may be supported in achieving a balance between holding a job and housekeeping, or finding time for rest and recreation while meeting the demands of parenting. 
Psychiatric rehabilitation has been shown to be an effective approach to enhance social functioning, housing stability and societal participation (Swildens et al., 2011; Gigantesco et al., 2006; Shern et al., 2000), but has not yet been widely studied in the context of parenting and parents' goals. In this paper, a small-scale pilot feasibility study is described. We examine the initial experiences with and impact of the PARSS intervention on parenting satisfaction and success, and on empowerment and quality of life for parents living with serious mental illnesses, compared with those receiving care as usual. This pilot study is intended not only to explore the benefits that can be gained from participation in PARSS, but also to identify adequate procedures and measures for implementing and evaluating an intervention of this type.

\section{The PARSS Intervention}

Key elements of the Parenting with Success and Satisfaction (PARSS) intervention include: (a) the psychiatric rehabilitation framework (Farkas \& Anthony, 1991); (b) a focus on enhancing self-regulation (Sanders \& Mazzucchelli, 2013); (c) structured strategies for proactive service to reach out to parents who express a need for support rather than waiting for a problem or crisis to occur (Weir, 2004); and (d) a transdiagnostic approach that suggests that certain fundamental processes underlie or transcend multiple psychiatric diagnoses. The intervention explicitly targets parental emotional regulation rather than diagnostic-specific characteristics as a useful strategy in developing interventions for families (Maliken \& Katz, 2013).

In the PARSS intervention, parenting is seen as a valued social role that is defined by individuals in their own ways. There is an explicit awareness of and respect for both the needs of the children, and the choices and constraints of their parents. Emphasis is placed on communicating well with others who are important to the parent and the child. Attention is also paid to effective communication with more formal supports, such as school personnel or 
representatives of agencies providing foster care to children. Parents may be reluctant to seek support from others - relatives or professionals - because they fear the negative attitudes and assumptions of others and possible loss of custody; this concern is discussed with parents before they begin the intervention.

PARSS is seen as an addition to other types of treatment and may be implemented in either inpatient or outpatient settings (Van der Ende et al., 2010). The training of mental health practitioners to implement PARSS takes a total of 4 days, with longer intervals between sessions in the last phase of the training. This is done to facilitate clinical supervision of the mental health practitioners when they start coaching. The PARSS intervention includes three workbooks for parents to help them achieve their parenting goals in a guided self-help approach. For parents, PARSS provides a way of working on self- selected goals for one's own well-being, in combination with a focus on the child's strengths and needs. Components of the intervention may be used by parents themselves as a self-help strategy. Other components of the intervention are best completed with the assistance of mental health practitioner (i.e., a social worker nurse or psychologist and, in some cases, psychiatrist).

\section{Workbook I. Assessing functioning in the parental role}

This workbook lays out explicit skills and recommended resources for carrying out the parental role for all parents. The chapters in this component are: Identity; Satisfaction and Success; Division of Time; and Attention and Commitment.

\section{Workbook IIa. Strengthening the parental role}

With the help of this workbook, parents who are living with their children are encouraged to describe what the parental role means to them. Workbook sections include: What does the Parental Role Ask of Me? Can I Satisfy These Demands? And Overcoming Barriers.

\section{Workbook IIb. Taking back or expanding the parental role}


This is designed for parents not living with their children. It focuses on exploring opportunities and situations specific to parents who live separately from their children. Based on the values and needs of the parent, opportunities and situations for dealing with the child are explored, particularly given that parents are not currently living with their children. The components are: My Needs as a Parent; The Possibilities for Me as a Parent; What Do My Choices Require? Can I Meet These Demands? Overcoming Barriers; and How to Go On.

Parents progress through the PARSS Workbooks with a mental health practitioner in ways that are adapted to their own situations and preferences, individually or in groups. In individual contact, work on parenting goals can be combined with a focus on other goals. If contact between a practitioner and a parent has a single emphasis on parenting goals, the entire intervention takes about a year on average, with weekly sessions. Before beginning the intervention, parents are informed of this commitment. PARSS is relevant to parents who are raising their children themselves, or to parents who have contact with their children through a custody and visitation arrangement. PARSS may also be useful to parents during or after a psychiatric hospitalization.

\section{Methods}

This pilot study employed a nonequivalent control group design. We used this design instead of a randomized control design that is more common in evaluation research. This was done for different reasons. Because of the risk of spillover, parents in contact with mental health teams with professionals trained in PARSS were only assigned to the experimental group. For the control group parents were included who had only been in contact with workers without a 
training. It was expected that, in the teams with PARSS-trained practitioners, an insufficient number of participants with an expressed need for rehabilitation support in parenting would be found for random allocation to either the intervention group or the control group. As a pragmatic solution, we chose to find parents with such an expressed need for support on parenting for the control group in organizations with practitioners who were interested but who had not received any training in PARSS. The design and accommodations were justified by the study focus on the pilot nature of the intervention.

\section{Recruitment of Participants}

PARSS training was provided in four mental health organizations. Practitioners could choose to participate in this training. Once they were trained, practitioners were asked to refer parents to the intervention group for the study. Only parents who explicitly stated they needed support in parenting were selected for participation in the study. The intervention group consisted of parents enrolled in PARSS. Four comparable mental health organizations in other parts of the Netherlands were asked to refer parents for the control group.

Recruitment was done in teams for long term care so as to select the specific group of especially parents with severe mental health problems. Parents with at least one child younger than age 21, who received mental health care and expressed a need for support in parenting issues, were recruited. In addition parents in the experimental group had to be willing to be coached by their mental health worker along the lines of the PARSS program. Since at the time of the evaluation study around 100 mental health professionals were trained in six organizations.

In four organizations permission was granted to perform the study. From these organizations parents from these organizations were recruited for the experimental group. In four other organizations professionals and parents were recruited to form the control group. One 
contact- person per organization was central and he or she was in contact with her (trained) colleagues. At the time a patient gave consent to participate the parental program with a patient started this was communicated with the researcher. The mental health practitioner working with the parent participated in an interview and parents were also invited to recommend a significant member of their network (e.g., a close family member) to be interviewed for the study. After this the trained professionals and parents in the experimental group started the PARSS program. In the control group professionals, not trained in this program, continued to work with the parent 'as usual', addressing parental issues in the way that they would regularly do. About two thirds received outpatient services and approximately one third received inpatient care or residential supports. There were no differences between the intervention and the control groups in the mental health disciplines of their involved providers. For $40 \%$ of the participants, care was provided by nurses and social workers; another $40 \%$ received treatment from both psychiatrists and nurses or social workers. In a few cases, a psychologist was involved.

Some mental health practitioners of parents in the control group reported providing support on parenting in an intuitive way, based on their own experiences as parents. The PARSS intervention was implemented in addition to services as usual in the intervention group. A recruitment period of one year was planned but with slow inclusion was extended with 6 months.

\section{Procedures}

Data were gathered in structured interviews with parents, their close relatives and their mental health practitioners at enrollment in the study (T0) and 1 year later (T1). Interviews were conducted by researchers and trained students. All participants gave written informed consent for participation. Study procedures were approved by the National Medical Ethics Board for Mental Health Care, Northern Region. 


\section{Measures}

The primary outcome variables were parenting satisfaction and success, empowerment, and quality of life. Parenting as defined in this study includes providing care, having empathy, enjoying recreation and play, setting boundaries and limits with children, and talking with children (Kendall \& Bloomfield, 2005). On all these dimensions, significantly more improvement was expected in the intervention group. The process variables included relationship with practitioner, quality of contact, satisfaction with the intervention, and a fidelity interview was conducted with PARSS practitioners. At inclusion patients were also asked to give information about their diagnosis.

\section{Parenting satisfaction}

Defined as self-efficacy in the parenting role, parenting satisfaction was assessed with the Tool to Measure Parenting Self-Efficacy (TOPSE; Bloomfield \& Kendall, 2007), completed by parents. This instrument measures parental competencies through self-report on the subscales of Affection, Play, Empathy, Routines, Control, Boundaries, Pressures, Acceptance, and Learning, using ratings from "0 - completely disagree” to 10 - “completely agree” on items such as "I am able to show affection toward my child” and "I am able to have fun with my child.” The original scale proved reliable $(\alpha=.89)$ and adequate for use in a pre- and posttreatment study (Bloomfield \& Kendall, 2007). The TOPSE was translated into Dutch according to the guidelines of the International Test Commission (Hambleton, 1994) using a “translation back-translation” procedure (Brislin, 1980). The translated version had reliability equivalent to the original for the total scale $(\alpha=.93)$ and for all but one subscale ( $\alpha$ 's from .69 to .84). In our sample the Pressure 
subscale proved unreliable $(\alpha=.36)$, possibly because of some negatively stated items. This subscale was left out of the analysis.

In an earlier study (Van der Ende, et al., 2010) a majority of parents with mental illnesses reported feeling challenged by finding a balance between parenting tasks and meeting their own needs, particularly in terms of having enough time and energy. Satisfaction with parenting was closely related to keeping this balance. Also, trust in one's own competency while facilitating or doing things with children was an important issue. In line with these findings, extra emphasis was given to these tasks in the PARSS training and two extra subscales were added to the original TOPSE: "Organizing Activities for Children" $(\alpha=.70)$ with items such as "I can arrange a daily routine for my child" and "Balance between parenting and one's own life" $(\alpha=.62)$ with items such as “There is a good balance between my needs and my parenting.” With these subscales added, the reliability for the entire scale was as high as the original version $(\alpha=.93)$.

\section{Parenting success}

Mental health practitioners and significant members of the parents’ networks were asked to rate their perceptions of how successful the parent was in coping with the parental role with the same items used in the TOPSE, reconstructed for use as an objective measure $(\alpha=.91)$.

\section{Empowerment}

Empowerment has been defined as a process by which people, organizations and communities gain mastery over their affairs (Rappaport, 1987). We included the measure of empowerment under the assumption that parents would also benefit from the intervention in a more global way (i.e., they would feel more empowered in general). To measure this concept, parents completed three subscales of the Psychological Empowerment Scale (PES; Akey 
Marquis, \& Ross, 2000, Dutch translation by Peter, Jacobs, \& Molleman, 2007): (1) attitudes toward control and competence; (2) cognitive evaluation of certain skills and knowledge; and (3) formal and informal participation. Mental health practitioners and family members completed a parallel version regarding participating parents, with items rewritten as an observation scale for these groups.

\section{Quality of life}

Two quality of life measures were used. A specific health-related measure, the WHOQOL-BREF (WHOQOL Group, 1998) assesses individuals’ perceptions of their position in life in the context of their culture and value systems and the effects of disease and health interventions on their quality of life (1998; Dutch version by De Vries \& Van Heck, 1997). A more generic measure, the EUROQOL-VAS, is a standardized, nondisease-specific instrument, often added in studies to complement more specific quality of life measures (Brooks, 1996).

\section{Relationship with practitioner}

Parents completed the Helping Alliance Scale to measure agreement on task orientation in the relationship between practitioner and parent, and to provide global evaluation of the relationship (HAS; Priebe \& Gruyters, 1993; Dutch translation by Wiersma in Catty et al., 2000).

\section{Quality of contact}

Questions were asked of parents to evaluate the relationship between parent and practitioner in terms of agreeableness, significance, access and sincerity. In addition, the total number of contacts between parent and mental health practitioner over the year was tallied. 


\section{Satisfaction with the intervention}

For parents in the PARSS group, an evaluation of the intervention was included in the 1year interview. Parents were asked whether they reached the goals they set for themselves at the start of the intervention. Both practitioners and family members of those in PARSS were also asked a small number of open-ended questions to evaluate the program and its possible effects.

\section{Fidelity}

The researcher conducted telephone interviews with practitioners after 1 year to assess the extent to which the PARSS intervention was conducted as intended. The interview included topics such as the extent to which parenting and empowerment were part of the conversation, and whether the balance between attention to children and time for oneself had become part of the support intervention.

\section{Analyses}

Cronbach’s alpha was calculated to test the reliability of the TOPSE translation.

Descriptive statistics and percentages were calculated, and $\chi^{2}$ tests and t-tests were used to describe and compare participants' characteristics. The means and standard deviations of the scores for the outcome variables at baseline (T0) and at 1 year (T1) were calculated. Baseline differences between the two groups were tested using independent t-tests. As the sample was too small to allow for multivariate analyses controlling for these differences, paired t tests were used to test the significance of differences within the groups from pre- to posttest ( $\mathrm{p}<.05$, one-sided). The SPSS 20.0 statistical software package was used (IBM Corp., 2011). Themes in qualitative responses to open-ended interview items were reviewed and compiled. 


\section{Participants}

A total of 26 parents participated in the study, 11 of whom were in contact with a PARSStrained mental health practitioner (see Table 1). All participants had an Axis I and/or an Axis 2 diagnosis and were in care for a duration of at least three years. Information from the interviews with parents and practitioners (nurses or social workers) showed that from this group four parents completed the program and three were still working on it: about halfway through the program

after 1 year. Four parents did end their participation beforehand: two had ended their contact with the mental health organization and two were working with their practitioners on more acute issues at the time of the interview, such as the death of a family member, divorce or the need to move to another house. 
Table 1. Characteristics of participants in PARSS and control groups $(\mathrm{N}=26)$

\begin{tabular}{|c|c|c|c|}
\hline & $\begin{array}{l}\text { PARSS-group } \\
\text { N=11 }\end{array}$ & $\begin{array}{l}\text { Control group } \\
\mathrm{N}=15\end{array}$ & $\chi^{2}$ test on categories \\
\hline \multicolumn{4}{|l|}{ Age } \\
\hline a. $21-30$ years & $5(46 \%)$ & $2(13 \%)$ & \\
\hline b. $31-40$ years & $4(36 \%)$ & $4(27 \%)$ & a vs. $b+c$ \\
\hline c. $41-52$ years & $2(18 \%)$ & $9(60 \%)$ & $\chi^{2}=5.1 \mathrm{df}=, \mathrm{p}<.05$ \\
\hline Gender & $10(91 \%)$ & $10(67 \%)$ & $\chi 2=2.1 \mathrm{df}=1, \mathrm{p}=.20$ \\
\hline \multicolumn{4}{|l|}{ Marital status } \\
\hline a. Married/in a relationship & - & $5(33 \%)$ & \\
\hline b. Divorced/widowed & $4(36 \%)$ & $6(40 \%)$ & $a+b$ vs. $c$ \\
\hline Unmarried & $7(64 \%)$ & $4(27 \%)$ & $\chi 2=3.4 \mathrm{df}=1, \mathrm{p}=.11$ \\
\hline \multicolumn{4}{|l|}{ Living situation } \\
\hline Together with partner & $0(-)$ & $5(33 \%)$ & \\
\hline Not with partner & $11(100 \%)$ & $10(67 \%)$ & $\chi 2=6.5 \mathrm{df}=1, \mathrm{p}<.05$ \\
\hline Living arrangement & $7(64 \%)$ & $10(67 \%)$ & \\
\hline \multicolumn{4}{|l|}{ Psychiatric diagnosis } \\
\hline a. Mood or anxiety disorder & $4(36 \%)$ & $9(60 \%)$ & \\
\hline b. Psychotic disorder & $1(9 \%)$ & $1(7 \%)$ & \\
\hline c. Addiction/Personality disorder & $5(45 \%)$ & $4(26 \%)$ & $\mathrm{a}+\mathrm{b}$ vs. $\mathrm{c}+\mathrm{d}$ \\
\hline d. Other & $1(8 \%)$ & $1(7 \%)$ & $\chi 2=.82 \mathrm{df}=1, \mathrm{p}=.36$ \\
\hline \multicolumn{4}{|l|}{ Duration of illness } \\
\hline 3-10 years & $6(55 \%)$ & $8(62 \%)$ & \\
\hline$>11$ years & $5(45 \%)$ & $5(38 \%)$ & $\chi 2=2.7 \mathrm{df}=1, \mathrm{p}=.67$ \\
\hline \multicolumn{4}{|l|}{ Highest education } \\
\hline a. University/college & - & $1(7 \%)$ & \\
\hline b. High school/ middle school & $3(27 \%)$ & $8(53 \%)$ & $\mathrm{a}+\mathrm{b}$ vs. $\mathrm{c}$ \\
\hline \multicolumn{2}{|c|}{ c. Elementary school/basic education 8 (72\%) } & $6(40 \%)$ & $\chi 2=2,9 \mathrm{df}=3, \mathrm{p}=.40$ \\
\hline Employment or other regular & $4(36)$ & $7(47)$ & $\chi 2=.27 \mathrm{df}=1, \mathrm{p}=.70$ \\
\hline \multicolumn{4}{|l|}{ Number of children } \\
\hline 1 & $6(55 \%)$ & $3(20 \%)$ & \\
\hline $2-4$ & $5(45 \%)$ & $12(80 \%)$ & $\chi 2=2.1 \mathrm{df}=1, \mathrm{p}^{>} .23$ \\
\hline Gender of youngest & $8(73 \%)$ & $9(69 \%)$ & \\
\hline \multicolumn{4}{|l|}{ Age of youngest child } \\
\hline a. $>5$ years & $7(64 \%)$ & $7(46 \%)$ & \\
\hline b. $6-11$ years & 4 (36\%) & 5 (33\%) & a vs. $b+c$ \\
\hline c. $>12$ years & - & $3(20 \%)$ & $\chi^{2}=.74 \mathrm{df}=2, \mathrm{p}=.39$ \\
\hline \multicolumn{4}{|l|}{ Legally responsible for the child } \\
\hline a. Participating parent & $7(64 \%)$ & $3(20 \%)$ & \\
\hline b.... and partner & $1(9 \%)$ & $7(47 \%)$ & \\
\hline c.... and foster parent & $2(18 \%)$ & $1(7 \%)$ & $a+b+c$ vs. $d$ \\
\hline d. Other than participating parent & $1(9 \%)$ & $4(26 \%)$ & $\chi 2=2.1 \mathrm{df}=1 \mathrm{p}=.19$ \\
\hline $\begin{array}{l}\text { Average number of } \\
\text { contacts with mental health }\end{array}$ & $24.0 \mathrm{SD}=4.2$ & $49.5, \mathrm{SD}=43.3$ & t-test $=-2.2 \mathrm{p}<.05$ \\
\hline
\end{tabular}


Comparing the characteristics of participants in both groups baseline differences were found. Both groups featured a greater number of women compared with men. In the PARRS group there are significantly more parents under 30 years old and more over 40 compared to the control group. ( $\mathrm{p}<.05)$. Only a few participants were married or in a relationship, with significantly more parents living without partners in the PARSS group $(\mathrm{p}<.05)$. In this group, level of education is lower and a greater number of families with one child are found but these differences did not reach significance. There were no differences where legal responsibility for the children was concerned. At T1 the control group had received significantly more contacts with mental health workers then the experimental group $(\mathrm{p}<0.05)$.

Parents in both groups met criteria for serious and disabling mental illnesses. Participants reported their primary mental health diagnoses based on the DSM-IV (American Psychiatric Association, 2000) classification as assigned by the clinician involved. The most common diagnoses reported were mood or anxiety disorders, personality disorders or addiction. Although many reported illness durations between 3 and 10 years, considerable percentages in both groups had lived with mental illnesses for 11 years or more. Most participants reported serious problems in more than one life domain (e.g., independent living, working, social contacts and parenting). Fewer than half, for example, were employed or had regular activities outside the home.

The characteristics of participants in both groups were similar. More women than men participated in the two groups. Fewer people over 40 years of age were found in the intervention group compared with the control group. Only a few study participants were married or in a relationship, with significantly more parents living without partners in the PARSS group. This was the only difference between groups reaching statistical significance. A greater number of families with one child were found in the PARSS group. Among the children in both groups, over two thirds were boys. Comparable percentages of participating parents and their partners were legally responsible for their children. 


\section{RESULTS}

\section{Primary Outcomes}

Parents' reports

Parenting satisfaction, as reported by parents via the TOPSE, increased between T0 and T1 in the PARSS group, whereas the mean scores of the parents in the control group remained almost the same over the year (see Table 2). However, this difference between groups did not reach statistical significance. The relatively large standard deviations indicate variation among participants. Examination of individual data revealed that half of all PARSS participants showed an increase in parenting satisfaction, whereas the other half were less satisfied after a year.

Empowerment as reported by parents on the PES was stable over the year in both groups. Quality of life as measured by the EUROQOL-VAS did improve, showing a significantly larger increase in the PARSS group in comparison with the control group. Parents' reports on the second quality of life measure, the WHOQOL-BREF, did not indicate any differences between groups. 
Table 2. Differences between baseline and results after one year for the intervention and control group

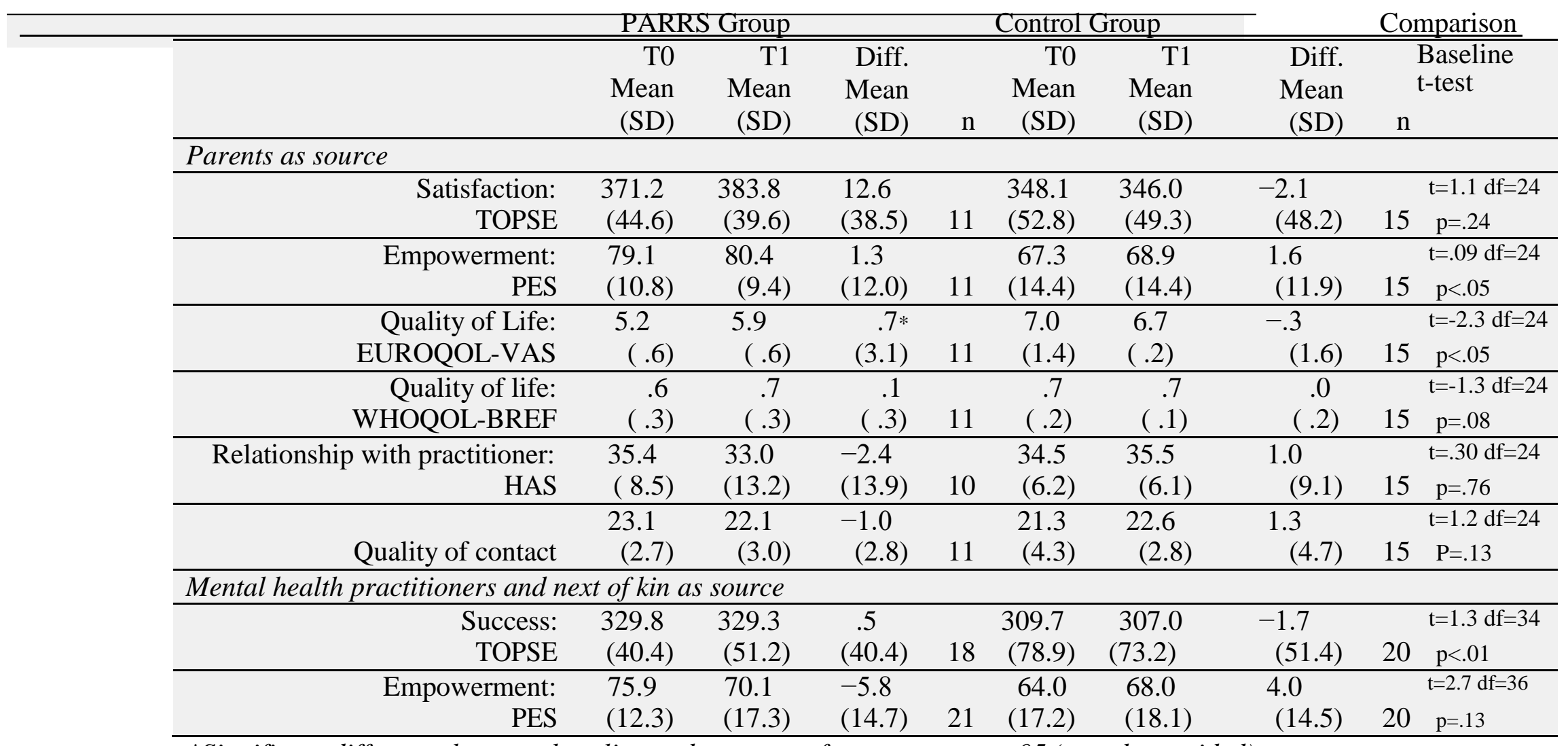

*Significant difference between baseline and outcome after one year, $p<.05$ (tested one-sided) 
At baseline significant differences between the groups in the main outcome measures are also apparent, with lower mean scores on success with parenting $(\mathrm{p}=<.05)$ and higher scores on empowerment $(\mathrm{p}<.05)$ for the experimental group. Parents in this group also rated themselves to be less successful in parenting $(\mathrm{p}<.05)$ than parents in the control group but were rated as more successful in this regard by others $(\mathrm{p}<.05)$.

At 1 year, practitioners' and family members' reports of parenting success were stable in the intervention group, whereas in the control group a slight improvement could be seen. With regard to empowerment, the scores for those reflecting on parents in the PARSS group started higher than for those regarding parents in the control group, but they decreased after 1 year, whereas the scores increased for the control group. Upon closer inspection, the seven parents in the PARSS group who did not complete the program had significantly lower empowerment scores as reported by practitioners and family members than reported for the four parents who completed the intervention.

\section{The Intervention Process}

\section{Relationship with practitioner and quality of contact}

There were no significant differences between the parent-reported scores at T0 and T1 regarding relationship with the mental health practitioner as measured by the HAS scores, nor in the scores on quality of contact between parent and mental health practitioner. This was the case in both the intervention and the control groups.

\section{Satisfaction with the intervention}

In the PARSS group, both parents and mental health practitioners were positive about the program. All the parents felt they received the support that they needed for parenting. They were more aware of their part in parenting, and had learned how to care for their 
children within their abilities. They had gained more insight into overcoming the problems they faced. Some of the parents expressed this as follows: "The program helped me to get a framework of support and means for parenting,” “[It was] instructive; I made progress in my role as a mother,” and “Nice and clear—it gives structure.” When asked whether they had reached the goals chosen at the start of the program, 9 out of 11 PARSS parents confirmed this was the case. Examples of their goals included: "being more confident with the kids,” "having more authority," "being free of the always claiming child," "giving structure” and “improving the relationship.”

In the 10 telephone interviews with the mental health practitioners from the PARSS group, all were positive about working with the intervention. They responded: "If the parent is open for it, the program is good. It is a professional program”; “It is very positive and applies to certain parents; it is not threatening"; "It makes you alert to what works with the parent." One case manager stated he had found greater fulfillment in his contacts with a father he was counseling. PARSS gave him more structure in his work and he could see progress being made in parenting.

\section{Fidelity}

Ten of the 11 PARSS mental health practitioners were interviewed regarding intervention fidelity. One of the practitioners could not be reached. All practitioners reported working with parents on the development of parenting skills, and on achieving a balance between parenting and leisure activities. As stated above however, only four of these10 practitioners completed the entire PARSS intervention with the parent. The others completed only the first workbook, with a focus on assessment, and did not implement the second part of the intervention, which focuses on strengthening or taking back the parental role. 


\section{Discussion}

In this pilot effect study, the outcomes of the Parenting with Success and Satisfaction (PARSS) program pre- and post- intervention outcome measures were available for 11 participants and corresponded to a one-year period. The outcomes were based on information provided by parents, professionals and persons in the network of the parents. Changes in satisfaction with parenting and in the empowerment and quality of life were based on selfreported information. To learn the specific effects of the program, this self-reported information was compared with recorded changes in these measures for 15 parents who were not enrolled in the program, but who had discussed parental issues with their caseworker. All 26 parents in the study received long-term outpatient care from a mental health center.

\section{Primary Outcomes}

PARSS was developed to enhance the possibilities of parenting for those living with severe mental illnesses. In the PARSS group, parenting satisfaction increased (i.e., showed a positive trend), but did not significantly differ from the control group. Self-reported quality of life changed on one of the two measures over the year in both groups, with a significantly greater change in a positive direction for the PARSS group compared with the control group. There were no significant changes in either group in parenting success as reported by mental health practitioners and family members. Empowerment as reported by parents did not show change. Practitioners and family members reported a greater change in empowerment for the control group parents, with no such change reported for the PARSS group.

The finding that, according to mental health practitioners and family members, parents in the control group showed an increase in empowerment, whereas the empowerment of PARSS parents decreased, is puzzling. Perhaps parents in the PARSS group, perceived as less empowered by their practitioners and family members, had become more dependent on these 
professionals. Parents in the control group gained more independence from their practitioners’ and family members’ perspectives. Further inspection of the PARSS group data made clear that the seven parents who did not finish the intervention had significantly lower scores than those who did complete it. It may be that empowerment is more strongly supported in later phases of the intervention.

Wary of the risk of over interpretation, we also suggest consideration of the ways practitioners can support parents to stimulate empowerment. If the tendency to dictate to parents about children's upbringing overshadows a more rehabilitation-oriented, empowering approach, the development of a sense of empowerment may be impeded by a lack of focus on the parent's own sense of control or independence. Practitioners must find a balance between, on the one hand, stimulating the development of and leaving responsibility to the parent and, on the other hand, taking responsibility for the situation where children are concerned, particularly if safety issues arise. However, when practitioners can see themselves as resources, with the parent in the leading role, some parental dependency on professional and natural resources can be fruitful. As Anthony and Farkas (2012, p. 41) state: “From a rehabilitation perspective, dependency is not a dirty word. Dependence on people, places, activities or things is a normal state of affairs.” When measuring empowerment one should note that, in the first phase of the intervention, parents may be more dependent on mental health practitioners. An increase in parents' empowerment may potentially be evident in later phases or at full completion of the intervention. Further studies are needed to discover whether this pattern is replicated in comparable situations.

All in all, there is some evidence that PARSS fills a gap in supporting parents with serious mental illnesses and psychiatric disabilities; outcome data provide evidence of positive trends. The instruments in this study seemed to be useful. Because the intervention is new and the pilot sample is small, more research with larger samples is necessary to fully 
assess outcomes and reach statistical significance. Given that the data from this small sample show great individual variability, qualitative and process-focused studies could provide more insight into who benefits from the program and why. Parents, mental health practitioners and family members evaluated PARSS as a useful approach, especially considering that, until now, no such intervention has been available.

\section{The Intervention Process}

Process and fidelity measures provided evidence that PARSS was fully implemented as intended only in some cases. Practitioners implemented PARSS with a small number of parents; they subsequently completed only portions of the intervention. The impression, from interviews, was that parents and practitioners began the intervention in a systematic way, but then priority shifted to other serious problems as they emerged. PARSS participants' attention may have moved on to another issue or topic, and away from a specific focus on parenting. The intervention was implemented in four mental health organizations or agencies, whose practitioners were trained in PARSS. The integrity and sustainability of the intervention was left to the organizations. Practitioners acknowledged they did not "stick" to the intervention all the time. More attention could have been paid to the implementation process by obtaining clear commitment from organization or agency management to implement the intervention, and by having one person per organization as the PARSS liaison.

Nonetheless, the outcomes indicate that a one-year program is too long for some of these parents. Only four of the ten parents completed the entire program. Evaluations with the workers are not reported, but were used to further develop the program and the training; we learned that workers should be aware of the influence of the professional context in which support is given to parents. Stimulating empowerment by a mental health professional was 
found to not always yield the desired effect in a situation in which parents are dependent on the services and support of this same mental health professional.

In retrospect, this study was conducted and outcomes were measured during a developmental phase when PARSS had not been fully implemented. This provided useful data, from an intervention development perspective, to inform further refinement and successful implementation in the future (Patton, 2011). Interventions developed and testing in community settings may be more generalizable and sustainable as they are brought to scale (Hoagwood, Burns, \& Weisz, 2002).

\section{Strengths and Limitations}

The strength of the PARSS intervention is that it explicitly focuses on supporting parenting, which is often a neglected domain in mental health services. Another strength is that the PARSS approach is built on the evidence-based practice of psychiatric rehabilitation (Swildens et al., 2011), and informed by theory and practice supported in the literature. PARSS provides clear goals and a structure for working together with parents. The subjective reports of participants indicate that PARSS is useful in terms of improving the balance of taking time for one's own life and meeting parenting demands. Mental health practitioners report improvements in their way of working. Our findings regarding the PARSS implementation process provide insight into recommendations for the future.

Attention must be paid to ensuring implementation of the intervention with fidelity to the model. Ongoing supervision groups and training booster sessions may be helpful to practitioners. A more specific fidelity measure should be developed. Attending to individual differences and variability among parents, and tailoring the intervention and evaluation in 
light of this variability should help to adapt PARSS to match participants' needs better and to demonstrate significant impact.

This pilot effect study has a limited number of participants (26). In the end 10 trained workers of the potentially 100 workers were able to refer patients, who actually participated in the study. For the control group, recruitment was done by mental health workers in four teams from other comparable mental health organizations. It is hard to give a sufficient answer as to why at the end only 11 patients could be included. Some of the possible reasons are: 1 ) practical: to make a good start, workers had to know about the wish of a parent to work on goals referring to their parental role but this could not already have been part of the support already given 2) on the parents side there could have been reluctance to follow a one-yearsprogram in parenting and being part of a study, 3) on the side of the professionals it could be discomforting to be part of an effectiveness study for such a new intervention. Possibly if there had been a financial compensation, recruitment would have been somewhat easier (cf Wansink et al. 2014). However we do think that the stigma around parenting with SMI and the fear of parents to explicitly share their worries and difficulties with professionals could be a reason that parents hesitated to enter the study. The fact that not only information was asked from parents and workers but also from a third party, for instance a family member of neighbor, was possibly an extra threshold to consent. Unfortunately there was no information on parents who declined participation so no non-response analysis could be made.

Although no formal criteria were used to only include parents with severe mental illness, the choice of recruiting via professionals working in long term care did result in a sample of parents who met at least two of the SMI criteria (a psychiatric diagnosis and dependent of care for a period longer than two years).

In this pilot study, the outcomes of the Parenting with Success and Satisfaction (PARSS) program pre- and post- intervention outcome measures were available for 11 
participants and corresponded to a one-year period. The outcomes were based on information provided by parents, professionals and persons in the network of the parents. Changes in satisfaction with parenting and in the empowerment and quality of life were based on selfreported information. To learn the specific effects of the program, this self-reported information was compared with recorded changes in these measures for 15 parents who were not enrolled in the program, but who had discussed parental issues with their caseworker. All 26 parents in the study received long-term outpatient care from a mental health center A significant difference in the change of the quality of life is found between the intervention group and the control group, the small sample size limits statistical impact. Several characteristics point to more disabilities among the participants in the experimental group in comparison to the control group e.g. unmarried, low education level, not living with a partner, and on the other hand a higher score on the empowerments scale. As for now it is not clear how this could have influenced the outcomes as, with these small numbers, no predictor analyses can be done. Such analyses could have shed a light on the influence of certain parent (or child or worker) characteristics that influence the outcomes, success and satisfaction with parenting. Within this information lacking two different hypotheses could be formulated. First, possibly for those parents with more severe problems the program leads to a more significant 'growth' i.e. increase in not only success and satisfaction where parenting is concerned but also an increase of empowerment and quality of life. On the other hand it could also be that this group has a harder time to develop their parental role and profits less from the intervention.

This pilot research indicates that the PARRS program can be used by mental health professionals. The results are mixed. Parenting satisfaction increased after one year for the PARSS group, not for the control group, and a significant difference in the change of the quality of life was found between the intervention group and the control group. The small 
sample size limits identifying additional statistical effects. The study is intended to inform

future studies.As this was a pilot study, larger controlled studies are needed, with special attention to tailoring the PARSS intervention and enhancing fidelity. Researchers in the

Netherlands as well as in other countries are hampered by the challenges in securing funding for both services and research with numbers of participants great enough to build the evidence base in traditional ways (e.g., large-scale, randomized control trials). In addition, the issues of empowerment and consumer choice in psychiatric rehabilitation may take priority over the random assignment of participants to conditions. These circumstances suggest the importance of collaboration within and across national boundaries to build the evidence base in creative ways on behalf of parents living with mental illness and their families.

\section{Conclusions and Implications for Practice}

Although the first experiences with the PARSS program were mixed, the PARSS intervention has the potential to function as a useful tool in supporting parents living with serious mental illnesses. As a guided, self-help intervention, it fills an important gap in available psychiatric rehabilitation resources for parents and practitioners. Important lessons were learned in this study regarding variability among parents and the implementation process.

\section{References}

Ackerson, B. J. (2003). Coping with the dual demands of severe mental illness and parenting: The parents' perspective. Families in Society, 84(1), 109-118.

Akey, T. M., Marquis, J. G., \& Ross, M. E. (2000). Validation of scores on the Psychological Empowerment Scale: A measure of empowerment for parents of children with a disability. Educational and Psychological Measurement, 60(3), 419438.

American Psychiatric Association. (2000). Diagnostic and statistical manual of mental disorders (4th ed., text rev.). doi:10.1176/appi.books.9780890423349.

Anthony, W. A., \& Farkas, M. D. (2012). The essential guide to psychiatric rehabilitation practice. Boston: Boston University Center for Psychiatric Rehabilitation.

Brislin, R. W. (1980). Translation and content analysis of oral and written material. In H. C. Triandis \& J. W. Berry (Eds.), Handbook of cross-cultural psychology 2: Methodology (pp. 389-444). Boston, MA: Allyn \& Bacon.

Bloomfield L., \& Kendall, S. (2007). Testing a parenting programme evaluation tool as a pre- and post-course measure of parenting self-efficacy. Journal of Advanced Nursing, 60(5), 487-493. doi: 10.1111/j.1365-2648.2007.04420.x 
Brooks, R. (1996). Euroqol: The current state of play. Health Policy, 37(1), 53-72. doi: 10.1016/0168-8510(96)00822-6

Catty, J., White, S., Koletsi, M., Becker, T., Fioritti, A., Kalkan, R., Lauber, C., Lissouba, P., Rössler, W., Tomov, T., van Busschbach, J.T., Wiersma D., Burns, T., \& EQOLISE Group. (2010). Therapeutic relationships in vocational rehabilitation: Predicting good relationships for people with psychosis. Psychiatry Research, 187(1-2), 68-73. Epub. doi: 10.1016/j.psychres.2010.10.018.

Craig, E. A. (2004). Parenting programs for women with mental illness who have young children: A review. Australian and New Zealand Journal of Psychiatry, 38(11-12), 923-928. doi:10.1111/j.1440-1614.2004.01482.x

De Vries, J., \& Van Heck, G. L. (1997). The World Health Organization Quality of Life Assessment Instrument (WHOQOL-100, 1997): Validation study with the Dutch version. European Journal of Psychological Assessment, 13, 164-178.

Farkas, M. D., \& Anthony, W. A. (1991). Psychiatric rehabilitation programs, putting theory into practice. Boston, MA: John Hopkins University Press.

Gigantesco, A., Vittorielli, M., Pioli, R., Falloon, I. R., Rossi, G., \& Morosini, P. (2006). The VADO approach in psychiatric rehabilitation: A randomized controlled trial. Psychiatric Services, 57, 1778-1783. doi: 10.1186/1745-0179-2-5

Hambleton, R. K. (1994). Guidelines for adapting educational and psychological tests: A progress report. European Journal of Psychological Assessment, 10(3), 229-244.

Hinden, B. R., Biebel, K., Nicholson, J., Henry, A., \& Katz-Leavy, J. (2006). A survey of programs for parents with mental illness and their families: Identifying common elements to build the evidence base. Journal of Behavioral Health Services \& Research, 33(1), 21-38. doi: 10.1007/s11414-005-9007-x

Hoagwood, K., Burns, B. J., \& Weisz, J. R. (2002). A profitable conjunction: From science to service in children's mental health. In B. J. Burns \& K. Hoagwood (Eds.), Community treatment for youth: Evidence-based interventions for severe emotional and behavioral disorders (pp. 327-338). New York: Oxford University Press.

Howard, L. M., \& Underdown, H. (2011). The needs of mentally ill parents - a review of the literature. Psychiatrische Praxis, 38(1), 8-15. Epub. doi: 10.1055/s-00301265976

IBM Corp. Released 2011. IBM SPSS Statistics for Windows, Version 20.0. Armonk, NY: IBM Corp.

Jones, S. Rachel, C., Matthew, S., Diggle, P. J., Dempsey, R., \& Sadhnani, V. ( 2013). A pilot web based positive parenting intervention to help bipolar parents to improve perceived parenting skills and child outcomes. Behavioural and Cognitive Psychotherapy [Epub ahead of print]. doi: 10.1017/S135246581300009X

Kendall, S., \& Bloomfield, L. (2005). Developing and validating a tool to measure parenting self-efficacy. Journal of Advanced Nursing, 51(2), 174-181. doi: 10.1111/j.13652648.2005.03479.x

Maliken, A. C., \& Katz, L. F. (2013). Exploring the impact of parental psychopathology and emotion regulation on evidence-based parenting interventions: A transdiagnostic approach to improving treatment effectiveness. Clinical Child Family Psychology Review, 16(2), 173-186. doi: 10.1007/s10567-013-0132-4

Mowbray, C. T., Oyserman, D., Bybee, D., MacFarlane, P., \& Rueda-Riedle, A. (2001). Life circumstances of mothers with serious mental illness. Psychiatric Rehabilitation Journal, 25(2), 114-123.

Nicholson, J., Albert, K., Gershenson, B., Williams, V., \& Biebel, K. (2009). Family options for parents with mental illnesses: A developmental, mixed methods pilot study. 
Psychiatric Rehabilitation Journal, 33(2), 106-114.

Nicholson, J., Biebel, K., Williams, V. F., \& Katz-Leavy, J. (2004). Prevalence of parenthood in adults with mental illness: Implications for state and federal policy, programs, and providers. In R. W. Manderscheid \& M. J. Henderson (Eds.), Mental health, United States, 2002. DHHS Pub No. (SMA) 3938 (pp. 120-137). Rockville, MD: Substance Abuse and Mental Health Services Administration.

Nicholson, J., \& Deveney, W. (2009). Why not support parenting? Psychiatric Rehabilitation Journal, 33(2), 79-82. doi: 10.2975/33.2.2009.79.82

Nicholson, J., Henry, A. D., Clayfield, J., \& Phillips, S. (2001) Parenting well when you're depressed: A complete resource for maintaining a healthy family. Oakland, CA: New Harbinger Publications.

Nicholson, J., Nason, M. W., Calabresi, A. O. and Yando, R. (1999). Fathers With Severe Mental Illness: Characteristics and Comparisons. American Journal of Orthopsychiatry, 69: 134-141. doi: 10.1037/h0080390

Patton, M. Q. (2011). Developmental evaluation: Applying complexity concepts to enhance innovation and use. New York, NY: The Guilford Press.

Peter, L, Jacobs, G., \& Molleman, G. (2007). Toolbox voor het meten van empowerment bij de einddoelgroep. [Toolbox for measuring empowerment at the target group]. Woerden: NIGZ.

Priebe, S., \& Gruyters, T. (1993). The role of the helping alliance in community care - a prospective study. The Journal of Nervous and Mental Disease, 181, 552-557.

Rappaport, J. (1987). Terms of empowerment/exemplars of prevention: toward a theory for community psychology. American Journal of Community Psychology, 15(2), 121$\underline{148 .}$

Reupert, A., \& Maybery, D. (2011). Programmes for parents with a mental illness. Journal of Psychiatric \& Mental Health Nursing, 18, 257-264. Epub. doi: 10.1111/j.1365 2850.2010.01660.x

Sanders, M. R., \& Mazzucchelli, T. G. (2013). The promotion of self-regulation through parenting interventions. Clinical Child Family Psychology Review. 1, 1-17. doi: 10.1007/s10567-013-0129-z

Shern, D. L., Tsemberis, S., Anthony, W., Lovell, A. M., Richmond, L., Felton, C. J., Winarski, J., \& Cohen, M. (2000). Serving street-dwelling individuals with psychiatric disabilities: Outcomes of a psychiatric rehabilitation clinical trial. American Journal of Public Health, 90, 1873-1878.

Swildens, W., Van Busschbach, J., Michon, H., Kroon, H., Koeter, M., Wiersma, D., \& Van Os, J. (2011). Effectively working on rehabilitation goals: 24-month outcome of a randomized controlled trial of the Boston Psychiatric Rehabilitation Approach. 